\title{
Systems-Based Approach to Neurological Health
}

\author{
A Clinical Conversation with David Haase, MD, and Robert Rountree, MD
}

David Haase, MD, is the founder and medical director of MaxWell Clinic, a personalized systems medicine clinic in Nashville, Tennessee. Dr. Haase received his medical training at Vanderbilt University and completed his residency in family medicine at Mayo Clinic in Rochester, Minnesota. He is double board certified in family medicine and integrative medicine and is among the first practitioners to be certified by the Institute for Functional Medicine. Dr. Haase is also the founder of the Food Initiative, a nonprofit organization that helps youth make healthier choices for their bodies and their communities. He is the Chief Medical Advisor for Xymogen, and consults for multiple laboratory, health care data, and clinical service delivery companies to drive innovation and better clinical outcomes. Dr. Haase teaches internationally about the root causes of disease and innovative safe treatments through his faculty position at The Institute for Functional Medicine as well as past adjunct appointments at the University of South Florida, University of Miami, and Western States University.

Robert Rountree: You have been in clinical practice for 24 years and have had quite a few accomplishments during that time. You have had a very successful clinic, you have written a book, and you have a faculty appointment with the Institute for Functional Medicine. So why did you want to go into medicine? Is it true that you grew up on a farm in South Dakota?

David Haase: Yes, a dairy farm. We milked cows every morning and night and we had a huge amount of land. I would sit in a tractor, and go up and down the field for hours on end and had a lot of time to contemplate the nature of the universe and nobody to talk to. So it led to a very active thought life. I realized later in my career that one of the main reasons I wanted to go into medicine was because I did not want to be bored!

Dr. Rountree: You were alone in the open air for hours on end?

Dr. Haase: Hours and hours and hours. And what that leads to is a deep knowingness of the land. I went into medicine largely because it seemed to be fascinating. I love biology. I love life and how it works. I figured out later that I got drawn into a systems medicine approach because it was really an agricultural approach. I recognized the deficiency of an approach that was just focused on treating disease, and instead wanted to have my life be an exploration of what creates health. Much like how one grows a crop, we literally grow health. It is the same natural process applied to a different set of organisms. And it just feels at home to me to keep asking the questions, how can I cultivate health? How can I grow a higher state of function?

Dr. Rountree: Your comments remind me of Dr. Daphne Miller, MD, author of the book Farmacology. Several years ago, she spoke at the Annual International Conference held by the Institute for Functional Medicine, during which she said that she believes every doctor should spend time on a farm. That it should be actually part of one's training as a doctor to work on a farm, so they can learn about applied ecology_among other things.

Dr. Haase: Absolutely. The number of things the farm teaches you is astounding. You know, the whole debate between Pasteur and Laennec - is it the seed or is it the soil that is responsible for disease? Yes, the seed can be a problem, but if the soil is bad, no seed is going to grow. Nothing can flourish.

I think that our endeavor in health care is to understand and to tend the soil, because you cannot control the wind, the rain, how much sunlight you have, but you can control how you plant, how you cultivate, how you nurture, the timing, the gentleness, and the generations you think about as you tend the land, because, you know, hey, my great-grandchildren are going to farm the same land. Our farm has been in the family for 140 years, and homesteaded by my great-great-great grandfather.

Dr. Rountree: What got you thinking outside of the box of your daily tasks?

Dr. Haase: I have been insatiably curious my entire life, and I do not know where that came from. I want to know everything about anything. I find it all fascinating. But actually, since I spent much of my life convinced that questions were a sign of ignorance rather than wisdom, I was really hesitant to ask as many questions as I wanted to. So I actually spent a lot of time thinking about my questions. I always wish that I would have been encouraged to ask more questions. That really was not an encouraged activitymaybe because I had a habit of asking really hard questions, Ha! So I had to do a lot of reading on my own. It was so boring in South 
Dakota that the highlight of my childhood is when we bought the World Book Encyclopedia set. I would sit down with that encyclopedia and just devour it, because it was like, "Whoa! Whoa! The world has order." I think that bringing order out of chaos is what humans are about. It is really what health care is about. How can we restore order-language and knowledge are forms of order that have a beauty. Seeking for understanding and order helps us respect reality and engage it more wholesomely.

Dr. Rountree: Was there anyone who was a particular mentor for you in the early years of your life?

Dr. Haase: Yes, my sister Diane. Diane was also the first person to go to college from our family. She pursued an advanced degree in physical therapy, ended up working at the Mayo Clinic in Rochester as a physical therapist, and she taught me so much.

She brought her zoology textbook home when I was in second grade, and that was my favorite book to this day. People ask me about it. "Well, what is your favorite book ever?" And I say, "The zoology textbook." Is life not amazing? Life finds a way and it is so complex and beautiful. I feel a deep privilege to get to interact with the complexity of the human experience.

So Diane, first of all, broke the seal on going to higher education, and so it was not something I had to fight for in my mind. I decided to leave the farm in second grade, and I gave my father written notice of this - that I will never be a farmer.

Dr. Rountree: Was your thinking that you wanted to do something in the field of health care, or did you say, "I want to be a doctor?"

Dr. Haase: My mom tells me that I wanted to be a doctor since I was little. I do not really recall that. But I had a lot of great interaction with my family doctor, Dr. Manuel Ramos, who was a Filipino surgeon, and manned all of the health care for our community. I had questions, and he loved to teach. He always got a kick out of me coming into the doctor's office.

He actually allowed me to come and join him in the operating room when I was in high school. I was his clinical assistant on an open cholecystectomy for a morbidly obese woman. You would think the farm and all the kind of grossness that happens on a farm would have prepared me for the inside of a warm human body. But, no, not so much! It was both horrifying and beautiful and entrancing and it was a heady experience. Dr. Ramos took me under his wing and taught me immunology when I got mononucleosis and was hospitalized. He taught me the immunology of mononucleosis, T cells, and B cells.

He said, "You should be a doctor." He kept telling me I should do that. I am not prone to listen to people very often, but I am glad I listened to him.

Dr. Rountree: What was medical school like for you? Did you feel like your teachers were right on, or did you feel like there was something more?

Dr. Haase: I loved it. I loved the knowledge. I loved the science behind it. I worked in the virology laboratory, and I got to do some great work in one of the earliest academic addiction treatment centers. I got exposure to so many interesting things. I loved medical school. But what I had come to learn later is that the process of specialization of doctors led to the partialization of humans. Specialists would focus on a small piece of puzzle, and I actually saw several people, or three people notably in my memory, which I recognized had actually died as a result of the specialist team that was looking after them, not seeing outside their own box. I was an observer kind of peripherally for all those cases. But it struck me just how much harm can occur in conventional medicine or in the care of sick patients, and also what a drive there was to never lose sight of the person, of that humanity that is in front of us.

So I went to one of the only two medical schools in the nation that does not have a family practice department, and I of course decided to specialize in family medicine, because I was not going to lose the big picture. However, I ended up going to the Mayo Clinic in Rochester, Minnesota, for my family medicine residency, because I wanted to be sure I was being trained and held to the highest standard in clinical medicine. I wanted breadth and depth. It is an amazing place to be trained as a generalist.

And that is when I met you for the first time Bob, when I was a resident at the Mayo Clinic. I am eternally grateful to you because you were the first "real" doctor who spoke the eloquence of the basic science of health care and who had a great heart and who was willing to look outside the box to help patients. I had not known an MD who had my similar training, who bridged the gap. I really give you a tremendous amount of credit for allowing me to take those next steps. Eternally grateful to you, Bob.

Dr. Rountree: Well, thank you for saying that. And I must say, you have taken everything you learned and proceeded to do pretty amazing things with your career. You have made it all work. Unfortunately, you know, there is an us-versus-them scenario that often happens in medicine-there is the mainstream, and then the tendency to think that anything outside of mainstream is alternative or fringe or flaky. I think people like you are a living example that you can love the science and love what mainstream medicine has to offer and just add onto it.

Dr. Haase: Absolutely. I actually think there is only one medicine, because there is only one reality. You know? I am not talking about the multiverse, ha! I think there probably should be exceptions if we go there. But I am going to limit myself to one universe in this conversation.

Since there is one reality, there is one medicine. And our job here is to figure out what is the best intervention for that one patient at that particular time. How can we help them in that process of reasserting their health? I do not really ever see an "us-versus-them" as fruitful. I think it is a false dichotomy. The bottom line is, we are here. I am here in the service of patients to experience health, either again or at a level they have not had before. Why on earth would I throw out tools that could be in a larger toolbox because somebody has a biased opinion about 
that? Do not get me wrong. I do not think everything is valid whatsoever. But we should not throw out a drug, procedure, philosophy, method, or opinion just because it does not fit well within the tribe in which we feel most comfortable.

Dr. Rountree: Yes, I totally agree. Now, isn't it true that you went to Nigeria and worked in a leper colony? How does that experience fit into your perspective?

Dr. Haase: Yes, absolutely. That was actually in college. I had the privilege to take a month to do a class in Nigeria. Health Care in a Third World Nation was the name of the class. I was the only sophomore premed student in this group of seniors who were all heading to medical school. The premed advisor took a liking to me and allowed me to come along.

We had an amazing experience, and it was there that I internalized that health care was not about codes, or medicines, or doctors, or tests. It was really about care, and I marveled at how much could be done with so little because it is the human that is designed to heal.

So, yes, I got to spend a couple days working in the leper colony and providing medications and education to this group of people. I worked in the TB ward for four days, and this is when HIV was not yet really understood to be rampant in Africa. So they did not understand why they had so many more TB cases than they used to. I did manage to depart Africa without HIV. I was fortunate. Many were not. Then I got to visit medical schools in Nigeria, and even participated in my first C-section. It turned out that I was not the least experienced medical person in the room at that time, as I had been involved in more surgeries at that point than the surgeon of record.

The need for medical training and medical services that are lifesaving is profound worldwide. We take so much for granted in the United States. I got to do these wonderful vaccine trips out into the hinterlands in rural health environments and saw how much love and joy served in the healing process. I went kind of expecting to see how bad things were. What it really taught me is just how amazing the human capacity to heal is and how much community, joy, love, compassion, and contribution can serve as powerful healing forces in the world.

Dr. Rountree: You came into medicine with this really big perspective. You were clearly a deep thinker who was very curious about the world at large. What made you want to practice in a relatively small town in Tennessee?

Dr. Haase: I spent some time at Mayo Clinic, but then quickly wanted to stretch my wings in rural primary care, which is what I really thought I went to medicine for. I went to a small town in Iowa called Cresco, and that is where my sister was a physical therapist. We got to practice together for many years.

That is where I had immense latitude to start integrating functional medicine, systems medicine, herbal medicine, and investigative medicine into my practice. I did regular family medicine, delivered babies, managed the home for the aged, ran a one-room ICU during snowstorms with dobutamine drips, and took care of major trauma coming in from the fields. We were about an hour and a half from any tertiary care facility. I really learned what it was to be a comprehensive physician.

I learned something very important there - that feedback is essential for us to have improvements. When a patient is at Mayo, or any other major center, if you go to a physician to help, and they do not help you with their recommendations, most patients do not come back and say, "That did not work." Instead, patients go find another doctor. The result is that you as a physician, having given advice and not getting feedback that your recommendations were not helpful, live with a hallucination that what you did was good, and so you do more of that. In a small town in Iowa, you get the feedback if things worked or did not work. And if it does not happen in the clinic, it happens in the grocery store, when you are at the football game, from a cousin, at church - everywhere feedback is there. I recognized very quickly, I was not such hot stuff. I had a lot to learn about doctoring and healing.

It was my failures in that practice that really drove me deeper into functional systems medicine, because my life's passion is to figure out how we create health for an individual at any given time. If we are not able to do that, we have to go back to the drawing board and ask better and different questions. And that is what I did. What transformed me was that curiosity in my failure to help people, which was learned through honest feedback that drove me to look for better solutions. Feedback is very important.

Dr. Rountree: One criticism of the kind of work that you and $I$ do is that functional medicine or integrative medicine is not for the working class. It is only for people who are well off or have time on their hands. It sounds like you have a response to that concern.

Dr. Haase: No, I do not agree with that idea. I did functional medicine in 15- to 20-minute visit increments, and I continue to train my clinicians who work at MaxWell Clinic — we have several doctors, nurse practitioners, physician assistants, registered dieticians, and health coaches who work in our clinic in Nashville right now and I am always harping on them, "What is the next best step for this person?" Oftentimes, we need to do less. I think there is a model that has pushed back against the six-minute primary care visit, and instead is like, "Oh, we need to do a two-hour intake and understand everything about this person." I disagree with that. I think that is a great way to learn how to think systems-ly, but that is not necessarily what is most effective down the road. As clinicians mature, they develop pattern recognition, and things become more efficient. I had the benefit of having to be more efficient and as a result seeing the value of helping people incrementally. I think I have the benefit of growing into this model as opposed to having a model of completeness kind of thrust upon me as practitioners who are new to the field experience.

I, myself, practiced inside insurance for 17 years. I just became nonparticipating with insurance two years ago for myself, but all the other practitioners in my practice are still participating inside insurance. Even though not all of what we do is covered, we are doing our best to make this systems medicine accessible to patients. 
Dr. Rountree: That serves as a lead-in to an ongoing question I have about the role of artificial intelligence (AI) in health care. You founded a company, MDOmics, which is focused on analyzing complex data sets using AI to enable precise clinical care. Some people say, "Wow, performing all that computational work with big data sounds very sophisticated, but isn't the resulting information extremely complicated to interpret and utilize? How on earth can you apply that to family medicine?" That is the burning question of our time, is it not?

Dr. Haase: It is the burning question of our time. I have been involved in several data aggregation and what I would call "clinical wisdom engines" over my years, and my work with MDOmics has been incorporated into some other projects at the present time, but what all of them have in common is this desire to be complete. And as such, they are necessarily insufficient. I see us building these clinical wisdom tools, and we have great hope for them. I think we hope that they are going to be so excellent because we know how much we forget on a daily basis, and we know how much better we could do medicine if our brains were bigger, et cetera. So these tools are emerging, many tools. My work with MDOmics has merged into a product called the MaxWell Brain MAP, and this is a tool for the multifactorial analysis and planning for the care of brain health, specifically dementia and Parkinson's.

Dr. Rountree: Brain health has really become a primary focus for you, has it not?

Dr. Haase: Yes, it has been really since about 2007. One day, all of a sudden it occurred to me how every symptom is a brain symptom. Quality of life is dependent upon brain function. I became one of the first functional medicine doctors to integrate quantitative electroencephalography and neurofeedback into our field - looking at the "soup" and "spark" one might say. This continues to be transformative for many people.

People who have been the functional medicine community for some time will recognize that the work that Dr. Dale Bredesen, MD, has brought into public discourse, David Jones, MD, David Perlmutter, MD, Catherine Wilner, MD, Jay Lombard, MD, yourself, and myself had been doing in our own ways many years before that. It has been wonderful to see more and more people get interested in this systems approach to brain care, and to say, "Huh, working on lots of little things can make a really big difference." That has been my current passion.

Bob, you mentioned about accessibility. I am really excited about MaxWell Brain MAP because we have been successful in actually making a basic form of this available at no cost to physicians, and no cost to patients through selected markets as we work with particular laboratories.

And, if the physicians utilize this tool, the report and the instructions that come with it enable them to bill Medicare and to implement comprehensive dementia care services! Now those physicians can actually get paid to do this more challenging work, and so we can start to crack the code on making systems medicine accessible to a larger population, which I think is incredibly important.
Dr. Rountree: I would love to get your take on this. I have had more than one client in the early stages of Alzheimer's dementia, who is often brought in by their family. They frequently ask about Dr. Dale Bredesen's popular ReCODE protocol. They are initially very interested, but when they actually get into the details, the client says, "Oh, my God, I have got to fix the 36+ holes in my ceiling and I have got to do all these very specific dietary interventions, while taking numerous supplements and it is all just too complicated." You know I mean? You are talking to someone who might be forgetting to eat some days, but you are telling them they have to be on this elaborate diet, while worrying about avoiding mold and environmental toxins. I am wondering how you navigate that situation.

Dr. Haase: Yes-Bob, you are asking exactly the right question. All too often the challenge is that in order for individuals to self-actualize a complex treatment care protocol, they need a good brain. The reason that they are in the office is that they are having problems with their memory, their executive function, their insight, and they are running off of deep fear, and the family is running off of deep fear. It is the most complex medical problem that one can engage. It really requires a family or caretaker that is deeply on board. It requires ongoing support, either through a nutritionist or health coach. And it requires a realistic understanding of the challenge of this.

We have had some quite remarkable successes, more than a few, and I do not think that everybody needs to do everything. It is not a magic list. It is a hypothesis generator. So, I am like, "You know, these are the potential areas, and let us do the best we can with where we are, and then let us also focus on the kids, because a small amount of effort earlier in life can have a tremendous impact." We now have better and better data, especially through Dr. Richard Isaacson, MD, out of the Weill Cornell US medical school-his Center for Prevention of Alzheimer's (https://weillcornell.org/services/neurology/ alzheimers-disease-memory-disorders-program/our-services/ alzheimers-prevention-clinic) has some great data on how simple things make a huge difference long term. It is a very well-curated database, and I have biased our system and recommendations deeply toward what he has shown to be of value, because I think we exhaust those things that are definitely shown to be of value first, and then move on to the more optional interventions.

Dr. Rountree: What have you identified as the major risk factors for dementia? Is it just having bad genes? Is it eating crappy food? Is it chronic undermethylation? What is your take on what is destroying our brains?

Dr. Haase: Right, so what a horribly hard question, because dementia is a state of multisystem collapse. Dementia is literally unbraining. That is what it means. We have massive resiliency in our neurologic systems. We have redundancy on redundancy. So when you start seeing that final collapse of what we know as the person, there have been a lot of things going wrong for a long period of time. 
So I want to give that caveat, because as soon as I give you an answer to this, I do not want anybody reading this to think, "Oh, that is the answer."

\section{Dr. Rountree: "Just take DHA, and you will be cured," right?}

Dr. Haase: Ha! We wish it were that simple. But regarding DHA who may benefit, and with how much, and how long do they need to do that? There is a definite benefit for omega-3 fatty acids, for people who have high levels over a long course of time, like a 15 -year time span. We have good observational data of how much red blood cell omega-3 fatty acids they have. But, you know, this problem that we have is a decades-long developmental problem. So whenever we are looking at interventions in the short term, they are almost always insufficient, except for one that I am going to tell you about later.

So you asked the question, what do I think is most important? What separates persons who have $\beta$-amyloid in their brain, but do not develop Alzheimer's from those who develop Alzheimer's is possibly immunosenescence. I really think it is the failure of the thymus gland, and the inability to hold back polymicrobial influences that are present.

Now, when you have vascular impairment-so, diseased blood vessels - you are necessarily going to have problems in that domain. I am going into detail here for a little bit, because one of the compounds that is made in the brain is cathelicidin, also known as LL-37. It is an antimicrobial peptide - in fact, the only antimicrobial peptide that functions inside the brain. When we are exposed to viruses, bacteria, or spirochetes, our body will make LL-37 and counteract and serve as a great defense mechanism against those organisms.

That ability to produce LL-37 diminishes over the course of time, either because of getting older or because of deficiencies of DHA, phytochemical activators, vitamin D, vitamin A, or butyrate. All of those have a part to play in this kind of cocktail to turn on this important protective molecule. LL-37 binds to $\beta$-amyloid, and in many ways keeps it from crystalizing. So if you have a decline in your body's native defense peptides, LL-37, you start making your backup peptides, $\beta$-amyloid. As amyloid fragments accumulate, they crystalize into organized $\beta$-type structures, and they start to impair both extracellular and intracellular function.

How do we get rid of the excessive $\beta$-amyloid 42 ? Each of us gets rid of it every day as it dumps out of our brain as we sleep through our glymphatic channels, the lymphatic channels discovered in the brain. As we enter deep sleep, we will actually detoxify the brain and dump out our excess amyloid fragments. Sleep starts to decline as we get older, and therefore we have less dumping of this $\beta$-amyloid and less cleaning out of the brain. So then anything that helps detox the brain - sleep is on the very top end - or anything that increases blood flow in the brain such as exercise increases the amount of exchange of the soluble $\beta$-amyloid, and that allows it to exit the brain and not accumulate.

But if you go back to the heart of all of that, why would the body start making more of this peptide? It is because it is trying to fight something off, and it is fighting something off with a mechanism that is inefficient. It is the backup plan of the backup plan. I think that it really kind of boils down to, if you have a robust immunotolerance and immunosurveillance system that is enabled by an adequate number and distribution of $\mathrm{T}$ cells, one does not need to depend upon LL-37 and then amyloid fragments. It is the thymus that I think that is probably our most important tipping point in this whole process.

You asked me what my top priority is, but I do not have one. I am a systems guy. Every person has a unique starting point and combination of interventions that are going to be most important given their particular causation constellation.

On the leading edge of interventions and investigations, I am now using regulatory peptides as interventions. I am involved in exosome research to change the genetic signaling patterns of immune cells. I am starting to track more and more patients using transcriptomics, so you see what the RNA expression pattern of the immune system is. All of those interventions continue to change my mind.

I would say that the most exciting intervention for Alzheimer's, I believe, is a new process that I have been researching in depth the past three years, which we are now doing in our clinic - the process of therapeutic plasma exchange for the treatment of Alzheimer's disease. I am a qualified apheresis medical director, along with my other varied trainings.

Apheresis is the procedure used to remove blood from the body, separate or manipulate it in some manner, and then return it to the body. What has been absolutely remarkable is that the data from one of the largest apheresis studies that has ever been completed have shown benefit in Alzheimer's disease. The study is called the AMBAR trial and it has shown that repeated apheresis has effectiveness in slowing the decline of moderate Alzheimer's by $60 \%$ for 14 months. In mild Alzheimer's, for that same 14 months, there was an improvement in memory, cognitive function, functional outcomes and behavioral outcomes, and improvement. This has not yet been published. It has been presented several times and I have been in discussions with the primary researchers. This is early science, but very promising.

I anticipate I am going to be teaching other doctors to do this, because it is a very complex procedure. The equipment is exceedingly expensive. The staff to run the procedure is expensive. The replacement fluids are expensive, and it takes a long time. It takes three to four hours every time one of these exchanges is completed. There is really nothing easy about this. But I think it holds a lot of hope. Currently, this procedure is really only available in tertiary medical centers for the treatment of advanced autoimmune diseases such as Goodpasture syndrome, Waldenström's macroglobulinemia, multiple sclerosis, neuromyelitis optica, and stiff man syndrome. All of these and many more have classic indications for therapeutic plasma exchange.

Dr. Rountree: What exactly is plasmapheresis taking out of the circulation?

Dr. Haase: This is something I am going to be talking a lot about-health is in the plasma. It goes straight to what Dr. Sidney Baker, MD, has always taught-how do you help 
this miraculous creation create health? Well, you remove things that are detrimental, and you replace things that are beneficial. That is what we are doing in plasma exchange. The blood is pulled out. It is mixed with an anticoagulant. It is separated into its different parts through centrifuge. The old plasma is separated and discarded. Then liquids that contain albumin and immunoglobulins are mixed with the red blood cells, and then those are put back into the patient's circulation. So you are literally doing the most complete detox procedure that could be done on human plasma.

There are so many more things to learn in this process, and this is one of the reasons I am investigating the proteomic and metabolomic outcomes of this process, because what is it that we are removing that is so harmful? We are actually removing, I think, "old" and replacing a neutral environment in that arena. At that time, the body is no longer getting senescent signaling from its own immune and stem cells. It then has a breather from kind of being nagged and told to inhibit growth, to inhibit the body - its own ability to heal. The stem cells are freed to start behaving normally. I have coined the term "Regenerative Plasma Exchange" to describe this process.

Dr. Rountree: There is research coming out now finding that senescent cells actually secrete all kinds of proinflammatory substances. It used to be thought they are inert, right?

Dr. Haase: You got it. And we are removing those.

\section{Dr. Rountree: You are not actually removing the senescent} cells, rather, you are removing their secretory products?

Dr. Haase: Correct, we are removing the exosomes, the peptides, and the neurosteroids, the hormones. It is a system that we are removing. The plasma is a system. It is a complex dynamic system that is balanced with itself and is really a major factor in our homeostasis.

I do not really like the word homeostasis because it includes being still. But it is that tonic signal to the body that this is your state at present. So if we change the inflammation flow to the body - and this is where I add onto Dr. Sidney Baker's summary - we also need to restore healthy signaling. That restoration of the signaling pattern is really what I think is going to move the needle for people. So it is literally out with the bad, in, at least, with the neutral. This is an "oil change for the brain."

Now, what is even more exciting is research into parabiosis. This is where - and I included this in my TED talk about a year and a half ago-you take two mice that are cloned, a young mouse and an old mouse, and you surgically attach them side by side and they are exchanging the microcirculation, not any big vessels, just a little bit of oozing going on back and forth. Within about a week, a remarkable thing happens. The old mouse starts to turn young. Hair starts to grow back in. Muscle strength improves. Liver function improves. Bone osteogenesis starts to occur, and neurogenesis kicks in. Astounding. At the same time, the young mouse is poisoned by "old." I put old in quotation marks. It is stunted. If the young mouse survives that exposure to a toxic milieu, it then recovers, and both mice are young - or healthy and happy. They are separated. The young mouse lives to its normal expected lifespan, and the old mouse lives to its expected lifespan, and in some studies a little longer.

Longevity has not been well studied. I would be really careful about how we extrapolate, but what we learned here is it is the signaling. I will be a little more broad and not just say senescent cells, because I think that is a part of this. I think that just like everything in medicine, we will learn we were wrong about that in some way. That is just what it is. But I think the fact that there is a signaling milieu that maintains old, maintains frail, maintains dementing is really the most important idea here. And so the question is, how can we mimic this process in a human? And we do that through therapeutic plasma exchange.

Dr. Rountree: It sounds like it could be useful not just for dementia, but also for a whole range of chronic diseases brought on by aging.

Dr. Haase: So the basic science in this is that when you change the milieu, you change the soil quality, and the seeds behave differently. I am thinking of the seed here as our stem cells. We still have stem cells, and those aged stem cells start to behave young again. We are really going to be looking for multitissue regeneration, if we get our signaling patterns correct.

So what would be the optimal replacement fluid? The optimal replacement fluid would be the plasma from a younger you, right? Teen plasma - we are remarkably indestructible at that age. Since that is impossible some doctors have said, "Okay, well, let us give patients infusions of young plasma from random donors."

Now, I will say that some of the small number of early advocates of "young blood" in their excitement did not attend to patient safety concerns as carefully as they should have, and patients were placed at unnecessary risk. However, there is now one blood bank in the United States that actually does age and sex segregate plasma to young healthy donors, and also does additional testing to see how immunoreactive that plasma may be. So the possibility does exist to do a therapeutic plasma exchange, and instead of replacing the old plasma with albumin, the replacement fluid would be the plasma from young healthy donors. This would be the most practical partial mimic of mouse parabiosis in a human. Now, let us be clear-there is absolutely risk with this. This would be bringing in another person's bodily fluid into your system.

So the optimal fluid would be the fluid from your young healthy self, but a secondary fluid would be the plasma from young healthy donors. And if you are going to do that, you are actually replacing the entire milieu, and you change the stem cell signaling of that aged or demented individual, we believe. That does need much more testing and research. There is so much to learn about this, but it is one of the most exciting times in the treatment of Alzheimer's that could possibly be present. I am convinced that the removal of unhealthy plasma is going to be a foundation of health preservation, almost universally. 
Dr. Rountree: You think apheresis may become a more common procedure in the future?

Dr. Haase: A mission of mine is to make apheresis ubiquitous, because I think that this is going to revolutionize how we think about systems of health. Now, let me come back. So this is all big technology, big expense, big-time commitment. Let us come back to the beauty of plasma. How else could we improve the quality of our plasma?

\section{Dr. Rountree: Would exosomes be another way to go?}

Dr. Haase: Absolutely, exosomes are tiny packets of information that have been produced inside a cell and then transported outside of that cell, go through the plasma and enter another cell to send an informational message. Exosomes will be huge. Peptides will be huge.

But I was getting a little bit more general because how else do we improve plasma? Well, we do it with exercise. We do it with fasting. We do it with improving the quality of our diet. We do it by decreasing our stress hormones, by making better choices, and by having robust relationships.

We change our plasma, which we, as doctors, check every day in people. Right? We are constantly checking the health of the body by measuring what is in the plasma. And we know that we change what is in the plasma by virtue of our health and lifestyle choices. By making more well-fitted health and lifestyle choices earlier, we create healthier plasma for the long term. And the earlier the better. The earlier and the more the better you are going to have long term.

Dr. Rountree: Lately I have really been diving into the work of Dr. Robert Naviaux, MD, PhD, at UCSD, on the metabolomics of people with chronic fatigue syndrome. The take-home message from his study is that there are all kinds of metabolites, like ceramides, that are distinctly abnormal in people with chronic fatigue. ${ }^{1}$ You cannot help but wonder, is this phenomenon only occurring in people with chronic fatigue, or is it that when we are unwell, there are variations on the same theme - that all kinds of metabolites start to go awry? That seems like what you are saying here.

Dr. Haase: Right. Exactly. So teasing out what is cause and effect, what is an antecedent, what is a trigger, and what is a mediator in each compound in the plasma is a great exercise to go through. And what is cause and what is effect?

What if we could just remove all those ceramides in the plasma? Would that individual's fatigue shift? I will tell you, our clinical experience has been quite remarkable as we have done apheresis. I have seen people get getter in ways that I was not expecting to occur. It has made me so acutely aware of just what IS this system that we have been able to hit a reset button on? It leads to far more questions than answers. And then whom may this benefit most? You know? So, again, more questions than answers. I am more excited about engaging and treating neurodegenerative disease than I have ever been in my life.
Dr. Rountree: There is a world of possibilities that is opening up here.

Dr. Haase: If we change our mindset to thinking of the plasma as our internal terrain, our cellular niche, our milieu, everything shifts. And this shift of mindset is totally congruent with lifestyle, integrative, and functional medicine because we are all endeavoring to improve the health of the plasma via less interventional means. Remember, I spoke earlier about how important it was for the glymphatics to allow drainage. We need to clean out the brain but if our plasma is full of junk, it stands to reason it may be more difficult for the brain to dump it out-maybe the gradient is impaired, the gradient is more difficult for the effective removal of these biological debris. We do not know. There is just so much we do not know.

Dr. Rountree: You have raised important questions that are going to start opening new doors. As we wind this discussion down, it occurs to me that the number-one thing that you are trying to impart to practitioners is the value of never settling into what you think is true. Never becoming too comfortable with our established beliefs; instead, maintaining an attitude of constantly saying, "Okay, which questions have we not asked about this particular issue?" Correct?

Dr. Haase: Absolutely. Our brains are our greatest resource, as well as our greatest prison. We have to use our brains to escape the prison of our own mind. And that goes for our views of who the patient is, our views of who we are as providers, and also our views of what is possible. Those are prisons in our own mind and they tend to be the worst prisons. This is a fearful place for me to tread because the prison of the mind that most people have with regard to dementia is that nothing can be done. We have come to be comfortable with that and that is how we order our entire world as we think of this.

So with something that actually may work and move the needle, but be highly inconvenient and not immediately accessible, there are going to be people who immediately have a negative emotional reaction to this, just because that is the law of cognitive dissonance. That is just the way it is. I am trying to prepare myself for that while still having integrity with my need to do what I can when I can with whom I am able to help.

Dr. Rountree: So your number-one message is to be curious. Never give up on your curiosity.

Dr. Haase: Yes, never give up, be very curious. And I will tell you that what has renewed my exuberance about treating Alzheimer's disease is that I recognize my life's mission is to find, enable, and protect wisdom. And wisdom is held in elders. If there is anything we need in today's day, it is that we need more wisdom.

We need the wisdom that only comes from age, but age with a brain that is highly active and capable. Curiosity is what actually helps to develop wisdom, and also hopefully we will strive to protect wisdom. So, yes, be curious, stay curious, and enjoy the ride. 


\section{To Contact Dr. David Haase}

David Haase, MD

E-mail: info@maxwellclinic.com

Websites: www.MaxWellClinic.com, www.DavidHaaseMD.com,

www.thefoodinitiative.org

Dr. Rountree: Thank you. I should mention a quote by Richard Feynman in the beginning of your book Curiosity Heals the Human ${ }^{2}$ that encapsulates everything you have said, "I would rather have questions that can't be answered than answers that can't be questioned." I thought that was an amazing quote and that would seem to characterize your entire career.

Dr. Haase: Amen. I am just filled with goosebumps. That is one of my favorite quotes.

Dr. Rountree: In addition to reading your book, Curiosity Heals the Human, ${ }^{2}$ which I highly recommend, how else can people follow your work? Do you have a blog that you encourage people to read?

Dr. Haase: To learn more about my work and thoughts visit my website - (www.DavidHaaseMD.com). You can also find me on Facebook at @DavidHaaseMD, or on Twitter@David HasseMD. I am also starting a podcast that is called "SUPERHUMANIZING," because I want to explore how health care is the journey to be more human, how do we humanize health care again, and also, what tools and thought leaders can make us the super-est human that we can be? It is going to be very exciting. Bob, you are one of the people I would like to interview on that podcast.

Dr. Rountree: I would be absolutely happy to do that. I also understand you are involved in a project called the Food Initiative.

Dr. Haase: Yes, $\sim 12$ years ago, my wife and our best friends cofounded this organization called the Food Initiative, (thefoodinitiative.org). This came out of my desire to see the creation of health addressed more upstream. We have been talking about a very downstream condition here, but how can we really create health upstream? Well, that is with our youth, and that is with our land.

So we have partnered with local businesses and community organizations and we recruit $\sim 40$ youth from our area per year. They apply to participate in our program. They will spend a month in groups of 10, and they will be coached along, and they work in the hot Tennessee sun, organic gardening.

Not only do they work in the garden, we have a health curriculum for them. We have a personal development curriculum and a food justice curriculum, so that we are helping them become aware of food distribution problems and food quality issues. They work and labor on the land together, they harvest the food, we teach them how to cook the food, and then they serve that food that they have cooked at our local hunger relief organizations.

We see a transformation in these amazing humans and remarkable leadership skills that come forth. We have exercises where they stand in a circle and look each other in the eye and say, "You know, Bob, I have observed you over the last week, and I have this positive for you. You did this well, and I have this delta for you, you know? I observed you not doing this well and not supporting the team," et cetera.

The paucity of direct communication in our world is killing us. So when these individuals learn to speak authentically yet kindly, transformative things can happen. And it is all transformed around the soil. It is around the garden and growing health, one youth at a time.

It is a joy to my heart and the community. The whole community of Clarksville, Tennessee, has really gotten behind it. We have raised $>\$ 1.4$ million over these years to support these youth, and we are always looking for additional donors. We would like to have that mega-donor come forth so that we can create our curriculum and enable other communities to do this, as well. Every time I speak about it, it certainly pulls at people's heartstrings. But I do not know anything about running a large nonprofit, and neither do our executive directors, although they are the best in the world at what they do in our local community.

Dr. Rountree: Well, that sounds amazing, and I have got an idea for your next book. It should be Lessons Learned from a Tractor Seat!

Dr. Haase: Exactly. Hold your breath when you are downstream from the exhaust. That is it. Exactly.

Dr. Rountree: I greatly appreciate your sharing all this with us and really look forward to working more with you in the future.

Dr. Haase: I always love that, Bob.

\section{References}

1. Naviaux RK, Naviaux JC, Li K, et al. Metabolic features of chronic fatigue syndrome. Proc Natl Acad Sci USA 2016;113:E5472-E5480.

2. Haase D. Curiosity Heals the Human: How to Solve "Unsolvable" Medical Challenges Using Better Questions and Advanced Technologies. Independently Published, 2018.

David Haase, MD, is the founder and medical director of MaxWell Clinic, in Nashville, Tennessee. Robert Rountree, MD, practices family medicine in Boulder, Colorado.

To order reprints of this article, contact the publisher at (914) 740-2100. 